\title{
Protein-bound polysaccharide K suppresses tumor fibrosis in gastric cancer by inhibiting the TGF- $\beta$ signaling pathway
}

\author{
TOSHIFUMI SHINBO ${ }^{1}$, SACHIO FUSHIDA ${ }^{1}$, TOMOYA TSUKADA ${ }^{1}$, SHINICHI HARADA $^{2}$, JUN KINOSHITA ${ }^{1}$, \\ KATSUNOBU OYAMA ${ }^{1}$, KOICHI OKAMOTO ${ }^{1}$, ITASU NINOMIYA ${ }^{1}$, HIROYUKI TAKAMURA $^{1}$, \\ HIROHISA KITAGAWA ${ }^{1}$, TAKESHI FUJIMURA ${ }^{1}$, MASAKAZU YASHIRO ${ }^{3}$, \\ KOUSEI HIRAKAWA ${ }^{3}$ and TETSUO OHTA ${ }^{1}$

\begin{abstract}
${ }^{1}$ Department of Gastroenterological Surgery, Division of Cancer Medicine, Graduate School of Medical Science, Kanazawa University, Kanazawa 920-8641; ${ }^{3}$ Department of Surgical Oncology, Osaka City University, Graduate School of Medicine, Abeno-ku, Osaka 545-8585, Japan
\end{abstract} \\ Kanazawa University, Kanazawa 920-8641; ${ }^{2}$ Center for Biomedical Research and Education, School of Medicine,
}

Received September 30, 2014; Accepted November 7, 2014

DOI: 10.3892/or.2014.3636

\begin{abstract}
Peritoneal carcinomatosis (PC) is the most frequent metastatic pattern of gastric cancer and its prognosis is extremely poor. PC is characterized by rich fibrosis and the development of obstructive disorders such as ileus, jaundice and hydronephrosis. Epithelial-mesenchymal transition (EMT) is one of the major causes of tissue fibrosis and transforming growth factor $\beta(\mathrm{TGF}-\beta)$ has a pivotal function in the progression of EMT. Protein-bound polysaccharide $\mathrm{K}$ (PSK) is a biological response modifier that can modulate the TGF- $\beta /$ Smad signaling pathway in vitro. In the present study, we established a fibrotic tumor model using human peritoneal mesothelial cells (HPMCs) and a human gastric cancer cell line to evaluate whether PSK attenuates tumor fibrosis. HPMCs exposed to PSK did not undergo the morphological change from a cobblestone-like pattern to a spindle-shape pattern normally induced by treatment with TGF- $\beta$. Immunofluorescence further demonstrated that PSK suppressed TGF- $\beta$-induced overexpression of $\alpha$-SMA in the HPMCs. We further showed that HPMCs contributed to the proliferation of tumor fibrosis by using a mouse xenograft model. Additionally, PSK treatment of these mice significantly reduced the area of observable tumor fibrosis. These results suggest that seeded cancer cells transformed HPMCs into myofibroblast-like cells through their release of TGF- $\beta$ in the microenvironment, facilitating the development of fibrous
\end{abstract}

Correspondence to: Dr Sachio Fushida, Department of Gastroenterological Surgery, Division of Cancer Medicine, Graduate School of Medical Science, Kanazawa University, 13-1 Takara-Machi, Kanazawa 920-8641, Japan

E-mail: fushida@staff.kanazawa-u.ac.jp

Key words: protein-bound polysaccharide, transforming growth factor $\beta$, gastric cancer, cancer-associated fibroblast tumors in organs covered with HPMCs. Therefore, our study indicates that PSK has potential utility as an anti-fibrotic agent in the treatment of gastric cancer patients with PC.

\section{Introduction}

Gastric cancer is a major global health concern, with an estimated 989,600 new cases and more than 738,000 attributable deaths in 2011 (1). Peritoneal carcinomatosis (PC) is a characteristic feature of gastric cancer and is a critical factor underlying its poor prognosis (2-4).

PC is relatively resistant to systemic chemotherapy due to the poor blood supply and oxygenation of cancer cells in the peritoneum (5). A large body of data has shown that systemic administration of S-1 or taxanes may be efficacious in treating PC. These compounds have a high sensitivity in targeting poorly differentiated adenocarcinoma, which is a common microscopic type of peritoneal tumor $(6,7)$. Furthermore, when administered intravenously, some of these compounds are transported into the peritoneal cavity $(8,9)$. Therefore, combining S-1 with intraperitoneal (i.p.) administration of taxanes has been proposed as an effective and feasible treatment strategy for PC. Ishigami et al established a protocol of i.p. paclitaxel with S-1 plus intravenous paclitaxel, in which the median survival time (MST) was 22.5 months and the 1-year survival rate was $78 \%$ (10). S-1 plus i.p. docetaxel also demonstrated a promising 1-year survival rate of $70 \%$, with an MST of 16.2 months in patients with severe PC (11). However, these clinical outcomes have been largely unsatisfactory since most patients die of recurrence within 5 years. PC is characterized by cancer cell infiltration and proliferation, which is accompanied by extensive stromal fibrosis. This results in the development of chemoresistance and obstructive disorders such as ileus, obstructive jaundice and hydronephrosis (12). Therefore, it is necessary to develop new treatment strategies to target the fibrosis in PC.

The fibrous tissue found in organs during PC is produced by cancer-associated fibroblasts (CAFs), which are recruited 
from orthotopic fibroblast pools (13), bone marrow-derived fibrocytes (14), and human peritoneal mesothelial cells (HPMCs) (15). These cells can undergo epithelial-mesenchymal transition (EMT) to differentiate into an extracellular matrix-producing myofibroblastic phenotype in the presence of TGF- $\beta$ released from gastric cancer cells (16). Therefore, TGF- $\beta$ signaling represents a promising potential target for tumor fibrosis in PC.

Protein-bound polysaccharide K (PSK; Krestin ${ }^{\circledR}$ ) is isolated and purified from the cultured mycelium of the Basidiomycete Coriolus versicolor (17). PSK is considered a biological response modifier, and has been approved for use in combination with chemotherapy to prolong the survival of patients with gastric cancer or colorectal cancer.

PSK also appears to inhibit TGF- $\beta$ signaling through suppression of TGF- $\beta$ production, direct binding with TGF- $\beta$, and through acting on TGF- $\beta$ receptors (18-20). Ono et al further reported that PSK can suppress Smad2 phosphorylation, resulting in the inhibition of EMT in the colorectal cancer SW837 cell line (21). Here, we investigated whether PSK could inhibit both the EMT-like change of HPMCs in response to TGF- $\beta$ signaling in vitro, and the subsequent induction of tumor fibrosis by co-inoculum of gastric cancer OCUM-2MD3 cells and HPMCs in vivo.

\section{Materials and methods}

Cell lines and cell culture. HPMCs were isolated from surgical specimens of the human omentum, as previously described (22). Written informed consent for use of these specimens, as required by the Institutional Review Board at Kanazawa University, Japan, was obtained from patients undergoing elective abdominal surgery. Small pieces of omentum were immediately washed extensively in phosphatebuffered saline (PBS) and were incubated in pre-warmed PBS containing $0.125 \%$ trypsin/EDTA (Gibco/Invitrogen, USA) for $30 \mathrm{~min}$ at $37^{\circ} \mathrm{C}$. The suspension was then passed through a $100-\mu \mathrm{m}$ pore nylon mesh (Becton-Dickinson, Japan) to remove undigested fragments and centrifuged at $1,500 \mathrm{rpm}$ for $5 \mathrm{~min}$. The collected cells were cultured in RPMI-1640 medium (Gibco/Invitrogen) supplemented with $20 \%$ heat-inactivated fetal bovine serum (FBS; Nichirei Bioscience Inc., Japan), $100 \mathrm{IU} / \mathrm{ml}$ penicillin, $100 \mathrm{mg} / \mathrm{ml}$ streptomycin (Gibco/Invitrogen), and $2 \mathrm{mM}$ glutamine (Nissui Pharmaceutical Co. Ltd., Japan). The cells were seeded in gelatin-coated $75-\mathrm{cm}^{2}$ flasks (BD BioCoat, USA) and cultured in $10 \mathrm{ml}$ of medium at $37^{\circ} \mathrm{C}$ in a humidified atmosphere of $5 \% \mathrm{CO}_{2}$ in air. Subconfluent HPMCs were trypsinized with $0.125 \%$ trypsin/EDTA before use. HPMCs were used from passage 1 to 3 in all experiments.

OCUM-2MD3, a cell line derived from a human scirrhous gastric cancer and with high peritoneal-seeding activity, was kindly provided by the Department of Surgical Oncology of Osaka City University of Medicine. OCUM-2MD3 cells were seeded in $75-\mathrm{cm}^{2}$ dishes (Becton Dickinson, Tokyo, Japan) and cultured in $10 \mathrm{ml}$ Dulbecco's modified Eagle's medium (Life Technologies, Tokyo, Japan) supplemented with $10 \%$ heat-inactivated FBS, $100 \mathrm{IU} / \mathrm{ml}$ penicillin, $100 \mathrm{mg} / \mathrm{ml}$ streptomycin, $2 \mathrm{mM}$ glutamine, and $0.5 \mathrm{mM}$ sodium pyruvate, at $37^{\circ} \mathrm{C}$ in a humidified atmosphere of $5 \% \mathrm{CO}_{2}$ in air.
Reagents. Protein-bound polysaccharide was kindly provided by the Kureha Chemical Ind. Co. (Japan) and TGF- $\beta$ was purchased from Sigma-Aldrich, Inc. (USA).

Phase contrast microscopy. HPMCs in cultures were treated with TGF- $\beta 1$ (10 ng/ml) or both TGF- $\beta 1$ and PSK (100, $500 \mu \mathrm{g} / \mathrm{ml}$ ) for $72 \mathrm{~h}$ and morphological changes were visualized by phase contrast microscopy. The images were captured using a Nikon inverted microscope (Nikon Corp., Japan).

Immunofluorescence. For visualization of E-cadherin and $\alpha$-SMA in the HPMCs, the cells were grown on 4-well, collagen type I-coated culture slides (BD BioCoat) and then fixed in a 1:1 mixture of methanol and acetone for $10 \mathrm{~min}$. Briefly, the slides were immersed in methanol containing $0.3 \%$ $\mathrm{H}_{2} \mathrm{O}_{2}$ for 30 min, blocked with $3.3 \%$ normal goat serum in PBS, and incubated with the E-cadherin antibody (H-108, rabbit polyclonal IgG; diluted 1:100; Santa Cruz Biotechnology, Inc., USA) and $\alpha$-SMA (1A4, mouse monoclonal IgG; diluted 1:100; DakoCytomation, Denmark) at $4^{\circ} \mathrm{C}$ overnight. Following three PBS washes, immunoreactivity was visualized by incubating the sections with an anti-mouse IgG antibody conjugated with Alexa Fluor ${ }^{\circledR} 488$ and an anti-rabbit IgG antibody conjugated with Alexa Fluor ${ }^{\circledR} 546$ (1:400; Molecular Probes/Invitrogen, USA) for $1 \mathrm{~h}$ at room temperature. Cells were then incubated with Hoechst 33258 for nuclear staining for $5 \mathrm{~min}$ and mounted with propyl gallate containing phenylenediamine under glass coverslips. Slides were observed with an immunofluorescence microscope (BX50/BX-FLA; Olympus, Japan).

Mouse xenograft model. All animal experiments were performed according to Kanazawa University's standard guidelines. Female immunocompromised BALB/c-nu/nu mice (4-6 weeks old; Charles River Laboratories Inc., Japan) with an average body weight of $20 \mathrm{~g}$ were maintained under sterile conditions and used for all in vivo experiments. OCUM-2MD3 cells were co-cultured with an equivalent number of HPMCs, and a total of $5 \times 10^{6}$ cells in $100 \mu 1$ of RPMI-1640 was then subcutaneously injected into the dorsal side of each mouse on day 0 . Mice were then divided into two groups: i) mice given normal chow (control, $n=10)$ and ii) mice given chow mixed with $1 \%$ PSK from day 1 (PSK, $n=10$ ). The PSK concentration within the chow was adjusted to be at a dose of approximately $1 \mathrm{~g} / \mathrm{kg}$ body weight/day, which was 1.5 -fold higher than the clinical dose of PSK ( $3 \mathrm{~g} /$ day) estimated by the surface area normalization method (23). Mice were allowed unrestricted access to water and to the standard or mixed chow. On day 15, the animals were sacrificed, and the tumors were harvested. Tumor specimens were collected for immunohistochemical examination.

Histological and immunohistochemical examination. Tumor specimens were fixed in 10\% neutral-buffered formalin and embedded in paraffin. Sections were stained with hematoxylin and eosin and Azan. To analyze fibrosis, Azan (blue)-stained areas were measured on a video display (magnification, $\mathrm{x} 200$ ) in a blinded manner using a QuickGrain digital image analyzer (Inotech, Hiroshima, Japan). Two sections were selected randomly from each sample and three fields from each section were evaluated; samples from 10 mice in each group 


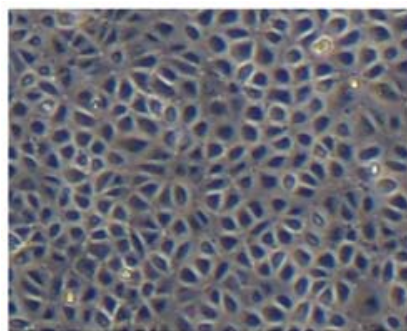

Control

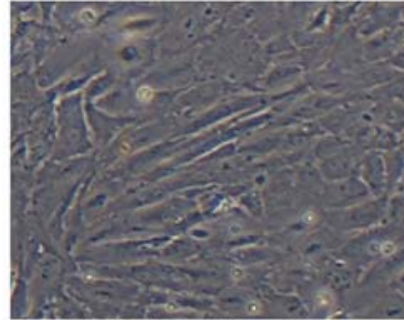

TGF $\beta 110 \mathrm{ng} / \mathrm{ml}$

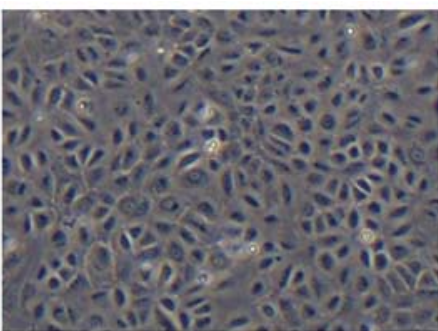

PSK $100 \mu \mathrm{g} / \mathrm{ml}$

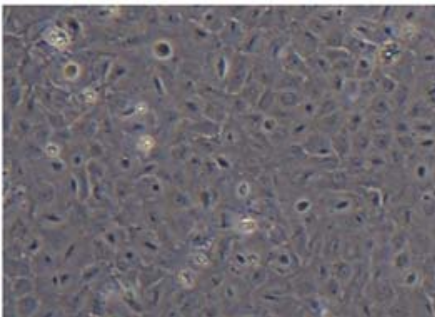

TGF $\beta 110 \mathrm{ng} / \mathrm{ml}$

PSK $100 \mu \mathrm{g} / \mathrm{ml}$

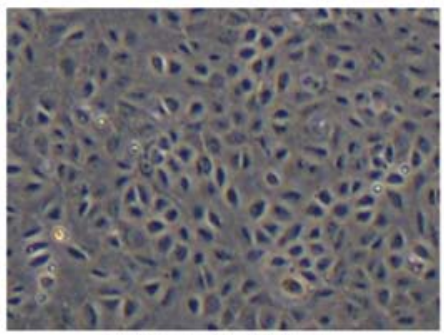

PSK $500 \mu \mathrm{g} / \mathrm{ml}$

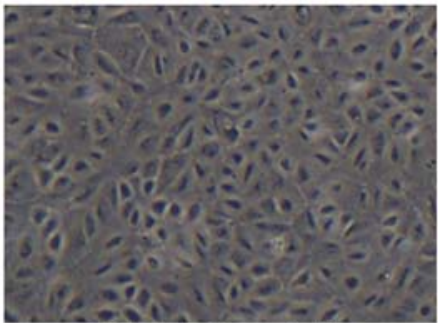

TGF $\beta 110 \mathrm{ng} / \mathrm{ml}$

PSK $500 \mu \mathrm{g} / \mathrm{ml}$

Figure 1. Representative image of morphological changes in HPMCs. (Upper left) HPMCs cultured in control medium. (Upper middle) HPMCs cultured in medium containing $100 \mu \mathrm{g} / \mathrm{ml}$ of PSK. (Upper right) HPMCs cultured in medium containing $500 \mu \mathrm{g} / \mathrm{ml}$ of PSK. (Lower left) HPMCs cultured in medium containing $10 \mathrm{ng} / \mathrm{ml}$ of TGF- $\beta$. (Lower middle) HPMCs cultured in $10 \mathrm{ng} / \mathrm{ml}$ of TGF- $\beta$ and $100 \mu \mathrm{g} / \mathrm{ml}$ of PSK. (Lower right) HPMCs cultured in $10 \mathrm{ng} / \mathrm{ml}$ of TGF- $\beta$ and $500 \mu \mathrm{g} / \mathrm{ml}$ of PSK. HPMCs cultured in each condition for $72 \mathrm{~h}$ were visualized by phase contrast microscopy at magnification, $\mathrm{x} 200$. HPMCs, human peritoneal mesothelial cells; PSK, protein-bound polysaccharide K.

were examined. To evaluate $\alpha$-SMA expression, the sections were immunostained with an $\alpha$-SMA antibody (1A4, mouse monoclonal IgG, diluted 1:100; DakoCytomation, Japan) at $4^{\circ} \mathrm{C}$ overnight, and treated with EnVision reagent (Dako Co. Japan) for visualization.

Statistical analysis. All data are expressed as mean \pm SD. Statistical analyses were conducted using SPSS statistical software, version 11.0 (SPSS, Inc., USA). Comparisons of drug effects were carried out using the Student's t-test. A p-value of $<0.05$ was considered to indicate a statistically significant difference.

\section{Results}

Effect of PSK on the morphological change in HPMCs following treatment with TGF- $\beta 1$. Control HPMCs exhibited a polygonal and cobblestone-like growth pattern, whereas HPMCs treated with TGF- $\beta 1$ adopted the spindle-shaped morphological characteristic of fibroblasts. Pretreatment with PSK blocked these morphological changes induced by TGF- $\beta 1$ in a concentration-dependent manner (Fig. 1).

Immunofluorescence examination. Expression of E-cadherin and $\alpha$-SMA were evaluated by indirect immunostaining and confocal microscopy. In the absence of TGF- $\beta 1$, HPMCs did not express $\alpha$-SMA in the cytoplasm. Treatment with TGF- $\beta 1$ induced cytoplasmic $\alpha$-SMA expression, a recognized component of EMT change. Pretreatment of HPMCs with PSK prior to TGF- $\beta 1$ administration prevented this EMT-like change (Fig. 2).

Histological and immunohistochemical examination of the xenograft tumors. Xenograft tumors resulted from the inocula- tion of BALB/c-nu/nu mice with a suspension of OCUM-2MD3 cells and HPMCs contained many $\alpha$-SMA-positive cells and a large amount of collagen fibers. Administration of PSK to these mice yielded a reduction in the number of $\alpha$-SMApositive cells and a decreased amount of collagen fibers (Fig. 3A). To semi-quantitatively evaluate the degree of tumor fibrosis, we examined the fibrotic areas in each tumor sample. Azan staining revealed a significant difference in the degree of fibrosis in the PSK group compared with the control $(\mathrm{p}<0.01$; Fig. 3B).

\section{Discussion}

The source of CAFs has not been fully elucidated. However, orthotopic fibroblasts and bone marrow-derived cells may function as myofibroblasts during EMT. In line with these findings, we previously reported that bone marrow-derived fibrocytes can contribute to tumor proliferation and fibrosis in gastric cancer (14).

In this present study, we demonstrated that HPMCs transformed into myofibroblast-like cells following exposure to TGF- $\beta$, and that these cells contributed to tumor-associated fibrosis. We previously demonstrated that HPMCs promoted fibrosis in a mouse xenograft model when co-inoculated with MKN45 cells (15). Together, these results suggest that HPMCs have a latent ability to function as CAFs and induce fibrosis in the tumor microenvironment in multiple cancer cell types.

Although orthotopic cancer-associated fibroblasts crosstalk with gastric cancer cells to enhance tumor progression, free cancer cells in the intraperitoneal cavity could produce peritoneal fibrous tumors in the absence of orthotopic fibroblasts. In PC of gastric cancer, seeded cancer cells attach to HPMCs and transform them into myofibroblast-like cells by releasing TGF- $\beta$. Spindle-shaped HPMCs can then facilitate 

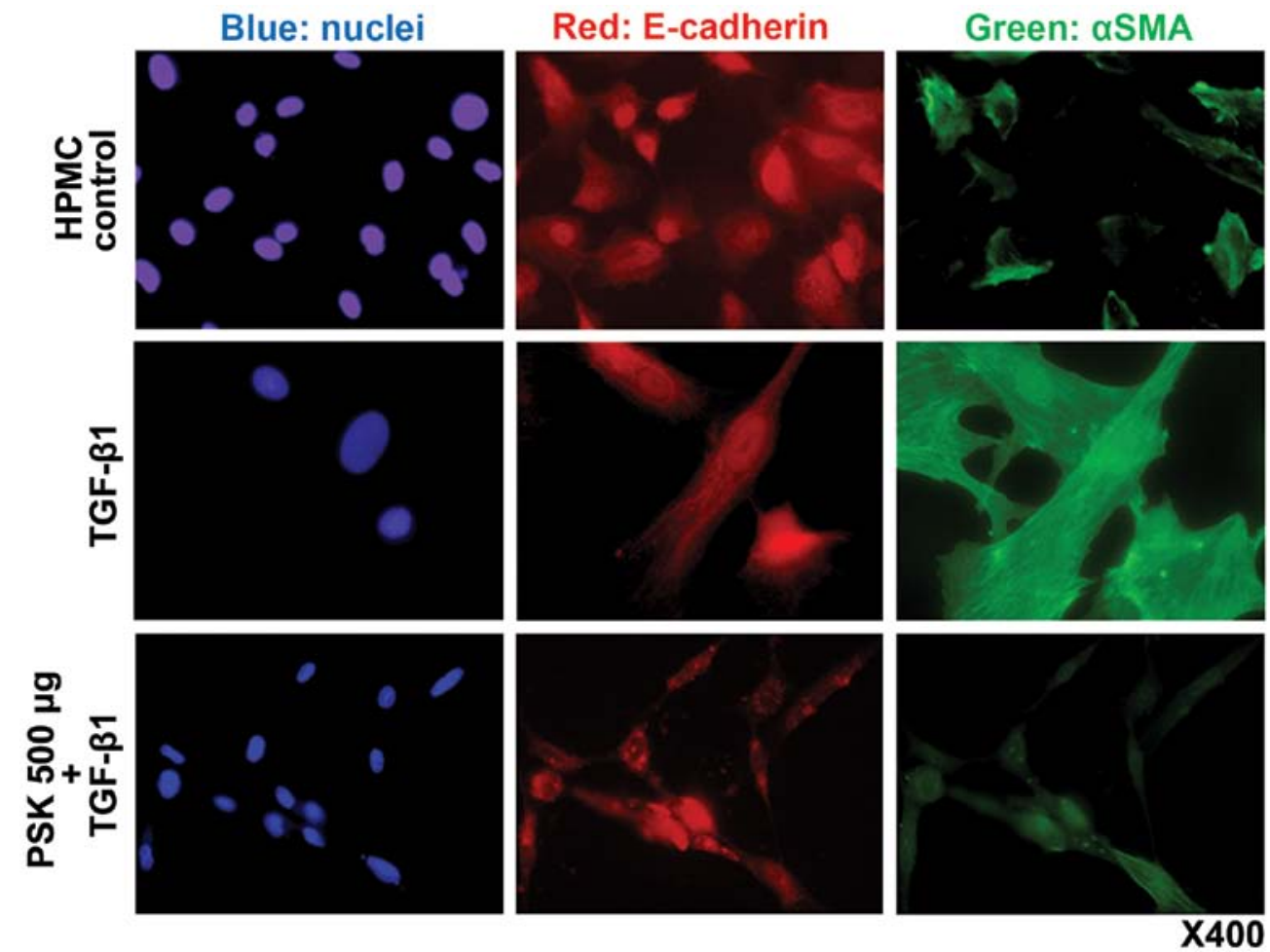

Figure 2. Representative photomicrographs of HPMCs, labeled with antibodies to E-cadherin (red) and $\alpha$-SMA (green). TGF- $\beta$-treated HPMCs showed increased expression of $\alpha$-SMA, whereas both TGF- $\beta$ and PSK-treated HPMCs showed almost equal expression of $\alpha$-SMA when compared with the control. HPMCs, human peritoneal mesothelial cells; PSK, protein-bound polysaccharide K.
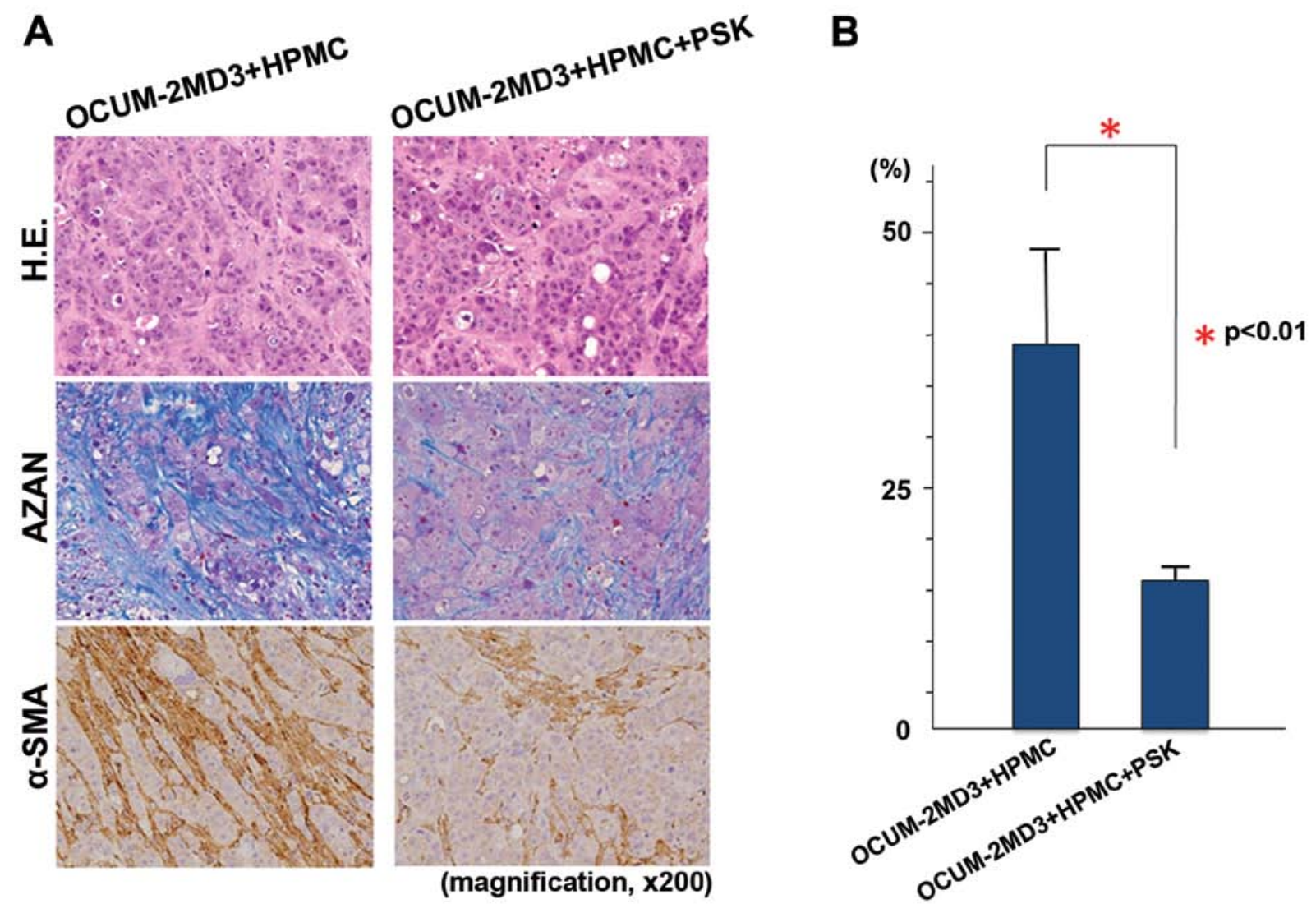

Figure 3. (A) Macroscopic views of mouse xenograft tumors. (Left panels) Xenograft tumors inoculated with OCUM-2MD3 cells and HPMCs contained much fibrous stroma showing blue color by Azan staining and many $\alpha$-SMA-positive cells. (Right panels) Subcutaneous tumors in mice treated with PSK revealed little fibrous stroma and a small number of $\alpha$-SMA-positive cells. (B) The fibrous area was measured semi-quantitatively. The PSK treatment group showed a significant low ratio of fibrosis when compared with the control (PSK not treated) group ( $p<0.01$ ). HPMCs, human peritoneal mesothelial cells; PSK, proteinbound polysaccharide K; H.E. hematoxylin and eosin. 
adhesion of cancer cells to the basement membrane and subsequently infiltrate the basement membrane as CAFs together with cancer cells. This concept is in agreement with the fact that PC can develop in any organ covered by HPMCs.

TGF- $\beta$ is regarded as one of the key molecules responsible for the differentiation of a variety of precursor cells to a myofibroblastic phenotype (24). Our results revealed that HPMCs also adopt an elongated spindle-shaped morphology from their normal cobblestone-like growth pattern, and exhibit overexpression of $\alpha$-SMA when exposed to TGF- $\beta$. This supports the notion that TGF- $\beta$ secreted from OCUM-2MD3 cells transformed HPMCs into myofibroblasts within the microenvironment of our co-inoculated mouse model, leading to the promotion of tumors with a fibrous stroma.

The control of TGF- $\beta$ signaling is required for the inhibition of organ fibrosis during PC, and for decreasing cancer invasiveness and metastasis. PSK is known to suppress TGF- $\beta$ signal transduction through inhibition of Smad 2 phosphorylation (21). We now demonstrated that PSK inhibited TGF- $\beta$-induced EMT-like change in HPMCs, and that fibrosis in xenograft tumors of PSK-treated mice was significantly reduced. Previous reports have shown that a TGF- $\beta$ neutralizing antibody and a TGF- $\beta$ receptor kinase inhibitor can both suppress EMT and reduce stromal fibrosis $(25,26)$. However, the long-term clinical use of these agents may lead to major complications due to the likelihood of adverse effects from interference with the many important roles of TGF- $\beta$ in normal tissues (27).

Previously, PSK has been thought to contribute to the maintenance of nutrition and immune strength in cancer patients during chemotherapy. As such, PSK has been approved for use in combination with chemotherapy to prolong the survival of patients with gastric or colorectal cancer. The effectiveness of PSK as a postoperative adjuvant for immunochemotherapy has been demonstrated by a meta-analysis (28). Here, the hazard ratio of 5-year survival was 0.88 (95\% confidence interval: 0.79$0.98, p=0.018)$, verifying that chemotherapy + PSK enhanced the survival of patients with curatively resected gastric cancer. These randomized clinical trials were conducted to examine the effectiveness of postoperative adjuvant immunochemotherapy compared with chemotherapy alone.

At present, S-1 is the standard agent for adjuvant chemotherapy for stage II and III patients with curative resected gastric cancer in Japan (29,30). The Hokuriku-Kinki Immunochemotherapy Study Group on Gastric Cancer is undertaking a clinical trial of S-1 alone versus S-1 plus PSK for curatively resected stage II and IIIA gastric cancer (31). It is expected that the S-1 plus PSK group will demonstrate longer survival times than the S-1 alone group in those patients with peritoneal recurrence.

To date, PSK has been widely used clinically in combination with chemotherapy without the observation of any serious side-effects. Therefore, it may hold promise as an anti-fibrotic agent for the treatment of gastric cancer patients with PC.

\section{Acknowledgements}

This study was supported in part by Grants-in-Aid for Young Scientists (B; 24791402 to J.K.) from the Japan Society for the Promotion of Science.

\section{References}

1. Jemal A, Bray F, Center MM, Ferlay J, Ward E and Forman D: Global cancer statistics. CA Cancer J Clin 14: 69-90, 2011.

2. Yamazaki H, Oshima A, Murakami R, Endoh S and Ubukata T: A long-term follow-up study of patients with gastric cancer detected by mass screening. Cancer 63: 613-617, 1989.

3. Chen CY, Wu CW, Lo SS, Hsieh MC, Lui WY and Shen KH: Peritoneal carcinomatosis and lymph node metastasis are prognostic indicators in patients with Borrmann type IV gastric carcinoma. Hepatogastroenterology 49: 874-877, 2002.

4. Maruyama K, Kaminishi M, Hayashi K, et al: Gastric cancer treated in 1991 in Japan: data analysis of nationwide registry. Gastric Cancer 9: 51-66, 2006.

5. Fushida S, Oyama K, Kinoshita J, et al: Intraperitoneal chemotherapy as a multimodal treatment for gastric cancer patients with peritoneal metastasis. J Cancer Ther 4: 6-15, 2013.

6. Osugi H, Takada N, Takemura M, et al: Oral fluoropyrimidine anticancer drug TS-1 for gastric cancer patients with peritoneal dissemination. Oncol Rep 9: 811-815, 2002.

7. Mai M, Sakata Y,Kanamaru R, et al: A late phase II clinical study of RP56976 (docetaxel) in patients with advanced or recurrent gastric cancer: a cooperative study group trial (group B). Gan To Kagaku Ryoho 26: 487-496, 1999.

8. Ohshima T, Yamada R, Hatori S, et al: Pharmacokinetics of S-1 in patients with peritoneal dissemination of gastric cancer. Oncol Rep 16: 361-366, 2006.

9. Naitoh H, Kawaguchi A, Yamamoto H, et al: Measurement of docetaxel concentration in blood and ascites after drip infusion into each vessel and intraperitoneal cavity of gastric cancer. Gan To Kagaku Ryoho 31: 2031-2034, 2004 (In Japanese).

10. Ishigami H, Kitayama J, Kaisaki S, et al: Phase II study of weekly intravenous and intraperitoneal paclitaxel combined with S-1 for advanced gastric cancer with peritoneal metastasis. Ann Oncol 21: 67-70, 2010.

11. Fushida S, Kinoshita J, Kaji M, et al: Phase I/II study of intraperitoneal docetaxel plus S-1 for the gastric cancer patients with peritoneal carcinomatosis. Cancer Chemother Pharmacol 71: 1265-1272, 2013

12. Tsukada T, Fushida S, Harada S, et al: Low-dose paclitaxel modulates tumour fibrosis in gastric cancer. Int $\mathrm{J}$ Oncol 42: 1167-1174, 2013.

13. Fuyuhiro Y, Yashiro M, Noda S, et al: Cancer-associated orthotopic myofibroblasts stimulate the motility of gastric cartinoma cells. Cancer Sci 103: 797-805, 2012.

14. Terai S, Fushida S, Tsukada T, et al: Bone marrow derived 'fibrocytes' contribute to tumor proliferation and fibrosis in gastric cancer. Gastric Cancer: May 4, 2014 (Epub ahead of print). doi: 10.1007/s10120-014-0380-0.

15. Tsukada T, Fushida S, Harada S, et al: The role of human peritoneal mesothelial cells in the fibrosis and progression of gastric cancer. Int J Oncol 41: 476-482, 2012.

16. Coussens LM and Werb Z: Inflammation and cancer. Nature 420: 860-867, 2002.

17. Tsukagoshi S, Hashimoto Y, Fujii G, Kobayashi H, Nomoto K and Orita K: Krestin (PSK). Cancer Treat Rev 11: 131-155, 1984.

18. Matsunaga K, Hosokawa A, Oohara M, Sugita N, Harada M and Nomoto K: Direct action of a protein-bound polysaccharide, PSK, on transforming growth factor-beta. Immunopharmacology 40 : 219-230, 1998.

19. Yamaguchi Y, Minami K, Ohshita A, Kawabuchi Y, Noma K and Toge T: Enhancing effect of PS-K on IL-2-induced lymphocyte activation: possible involvement of antagonistic action against TGF-beta. Anticancer Res 24: 639-647, 2004.

20. Zhang H, Morisaki T, Matsunaga H, et al: Protein-bound polysaccharide PSK inhibits tumor invasiveness by down-regulation of TGF-beta1 and MMPs. Ciin Exp Metastasis 18: 343-352, 2000.

21. Ono Y, Hayashida T, Konagai A, et al: Direct inhibition of the transforming growth factor- $\beta$ pathway by protein-bound polysaccharide through inactivation of Smad2 signaling. Cancer Sci 103: 317-324, 2012 .

22. Yung S, Li FK and Chan TM: Peritoneal mesothelial cell culture and biology. Perit Dial Int 26: 162-173, 2006.

23. Reagan-Shaw S, Nihal M and Ahmad N: Dose translation from animal to human studies revisited. FASEB J 22: 659-661, 2008.

24. Evans RA, Tian YC, Steadman R and Philips AO: TGF-beta1mediated fibroblast-myofibroblast terminal differentiation - the role of Smad proteins. Exp Cell Res 282: 90-100, 2003. 
25. Shinto O, Yashiro M, Kawajiri $\mathrm{H}$, et al: Inhibitory effect of a TGFbeta receptor type-I inhibitor, Ki26894, on invasiveness of scirrhous gastric cancer cells. Br J Cancer 102: 844-851, 2010

26. Ly ZD, Wang HB, Dong Q, et al: Mesothelial cells differentiate into fibroblast-like cells under the scirrhous gastric cancer microenvironment and promote peritoneal carcinomatosis in vitro and in vivo. Mol Cell Biochem 377: 177-185, 2013.

27. Roberts AB and Sporn MB: The transforming growth factor- $\beta$ s In: Peptides, Growth Factors and Their Receptors Part I. Sporn MB and Roberts AB (eds.). Springer-Verlag, Berlin, pp419-472, 1990.

28. Oba K, Teramukai S, Kobayashi M, Matsui T, Kodera Y and Sakamoto J: Efficacy of adjuvant immunochemotherapy with polysaccharide $\mathrm{K}$ for patients with curative resections of gastric cancer. Cancer Immunol Immunother 56: 905-911, 2007.
29. Sakuramoto S, Sasako M, Yamaguchi T, et al: Adjuvant chemotherapy for gastric cancer with S-1, an oral fluoropyrimidine. N Engl J Med 357: 1810-1820, 2007.

30. Fujii M, Kochi M and Takayama T: Recent advances in chemotherapy for advanced gastric cancer in Japan. Surg Today 40: 295-300, 2010.

31. Ueda Y, Fujimura T, Kinami S, et al: A randomized phase III trial of postoperative adjuvant therapy with $S-1$ alone versus S-1 plus PSK for stage II/IIIA gastric cancer: Hokuriku-Kinki Immunochemotherapy Study Group-Gastric Cancer (HKIT-GC). Jpn J Clin Oncol 36: 519-522, 2006. 